\title{
Educação escolar indígena e educação escolar não indígena: ponto de convergência, o PB
}

Indigenous school education and non-indigenous school education: point of convergence, Brazilian Portuguese

\author{
Antonio Almir Silva Gomes ${ }^{1}$ \\ Universidade Federal do Amapá \\ Núcleo de Estudos de Línguas Indígenas (NELI-UNIFAP/CNPq)
}

RESUMO: Do ponto de vista legal, é perfeitamente possível contrastar os sistemas educacionais escolares indígena e não indígena brasileiros, uma vez que aquele, através da LEI N ${ }^{0}$ 10.172, de 9 de janeiro de 2001, é garantido, em detrimento deste, o direito a "regimentos, calendários, currículos, materiais pedagógicos e conteúdos programáticos adaptados às particularidades étno-culturais e linguísticas", bem como "suas línguas maternas e processos próprios de aprendizagem". Um tema, no entanto, permite aproximar os dois sistemas: a presença do Português Brasileiro em seus interiores em "formato de disciplina". No caso do sistema escolar indígena, tem sido tratado, sobretudo no ambiente acadêmico, sob o rótulo "Português Indígena". Em termos estruturais / gramaticais, a natureza deste português contrasta aparentemente com o que se convencionou chamar "Português Culto / Padrão". Meu propósito neste artigo é chamar a atenção para a natureza estrutural do "Português Indígena" (Cf. GOMES, 2012), assemelhando-a a outras modalidades de português. Consequentemente, discuto o lugar desta língua no interior da escola indígena em seus princípios norteadores, bem como o papel da escola não indígena no contexto da formação de seus cidadãos perante o usuário indígena desta língua.

Palavras-Chave: Escola Indígena. Português Brasileiro. Ensino.

ABSTRACT: From the legal point of view, it is perfectly possible to contrast indigenous and non-indigenous brazilian school education systems, since, through the Law $\mathrm{n}$. 10.172, of January 9, 2001, the indigenous school education system conquered the right to "regiments, calendars, curricula, teaching materials and program content tailored to ethno-cultural and linguistic particularities as well as their mother tongues and their own learning processes". A theme, however, allows us to approach the two school education systems: the presence of Brazilian Portuguese in their classrooms as a "discipline". In the case of the indigenous school education system, the Portuguese has been treated under the label "Indigenous Portuguese". In its grammatical struc-

\footnotetext{
${ }^{1}$ Agradeço ao CNPq pelo financiamento da pesquisa relacionada a processos de ensinar e de aprender línguas que venho realizando junto aos povos Galibi-Marworno e Karipuna que vivem na Terra Indígena Uaçá às proximidades do município de Oiapoque, estado do Amapá (Edital Universal 2016, Processo n. 424117/2016-9). A pesquisa em questão tem me permitido pensar de maneira mais contínua questões relacionadas às aulas de línguas em contexto indígena, incluído o texto que constitui esse artigo. As ideias preliminares deste artigo foram apresentadas em conferência - com o mesmo nome (do artigo) - por mim proferida na programação do I Fórum Regional de Estudos e Pesquisas Aplicas (I FEPLA) realizado nas dependências da Universidade Federal do Amapá em 2017.
} 
ture, the nature of the "Indigenous Portuguese" contrasts with what is conventionally called "Pattern Portuguese". My aim in this paper is, based on Gomes (2012), to draw attention to the structural nature of the "Indigenous Portuguese", resembling it to other Portuguese modalities. Consequently, I discuss the place of this language within the indigenous schools, as well as the role of the non-indigenous school in the context of consciousness of different forms of use of Portuguese.

Keywords: Indigenous Schools. Brazilian Portuguese. Teaching.

\section{Introdução}

O Brasil é detentor de aproximadamente 220 povos (Cf. CENSO IBGE, 2010) e 150 línguas indígenas distintas (Cf. Moore, Galucio e Gabas Jr, 2008) ${ }^{2}$, o que o coloca no contexto da América do Sul como possuidor da maior diversidade linguística. No que se refere à escola destes povos, a Educação Escolar Indígena (EEI), do ponto de vista legal tem sido pensada, conforme Gomes (2013, p. 272), "sob os pilares da diferenciação, especificidade, interculturalidade e bilinguismo...". Como consequência, pode-se depreender como direitos adquiridos pela EEI a utilização de "regimentos, calendários, currículos, materiais pedagógicos e conteúdos programáticos adaptados às particularidades étno-culturais e linguísticas" (cf. LEI No. 10.172, de 9 de janeiro de 2001). Além disso, "suas línguas maternas e processos próprios de aprendizagem", bem como a presença de professores índios na escola indígena são garantidos (cf. CONSTITUIÇÃO FEDERAL de 1988, § 20 do artigo 210).

As conquistas mencionadas dos povos indígenas brasileiros constituem o momento atual de seus programas de educação escolar. Esse momento contrasta com momentos anteriores. Considerando-se a cronologia desta modalidade de educação a partir de Ferreira (1992), estaríamos vivenciando agora um quarto momento, precedido pelo (1) período colonial, centrado na "catequização" dos indígenas; (2) pelas ações do Serviço de Proteção aos Índios (SPI), centradas na "assimilação" dos indígenas à sociedade nacional; e (3) pelo período da Ditadura Militar, em que se nota a atuação de organizações não governamentais junto a populações indígenas, bem como de universidades brasileiras.

Outro panorama histórico da EEI nacional pode ser encontrado, por exemplo, em Kahn e Franchetto (1994), para quem os anos de 1980, com as lutas e reivindicações das lideranças indígenas, apoiadas pela sociedade civil, marcam uma mudança na trajetória desta modalidade de educação. Segundo as autoras,

"Até os anos 70, podemos identificar um projeto claro, explicito e pragmático que norteou a Educação Indígena no Brasil: catequese e socialização para a assimilação dos índios na sociedade brasileira...O lema era integrar,

\footnotetext{
${ }^{2}$ É necessário observar de antemão a inexistência de um número exato referente à quantidade de línguas indígenas brasileiras. Isso se deve a inúmeros fatores ainda discutidos no âmbito da linguística, por exemplo, a falta de clareza, para alguns casos, acerca do que seja língua, ou do que seja dialeto de uma mesma língua. Diante disto, o leitor notará ao longo do texto menção a um segundo número relacionado à quantidade destas línguas, 180.
} 
civilizar o índio, concebido como um estrato social submetido a uma condição étnica inferior, quando vistos nos moldes da cultura ocidental cristã." (KAHN e FRANCHETTO, 1994, p. 6)

\section{Ainda segundo Kahn e Franchetto, op. cit., o panorama histórico descrito}

“... se confirma quando os órgãos oficiais de tutela - o Serviço de Proteção ao Índio (SPI) e depois a Fundação Nacional do Índio (FUNAI) - estabeleceram convênios com instituições religiosas de diferentes credos, para que elas se incumbissem de implantar o trabalho escolar dentro das aldeias. 0 Estado tutor jamais se preocupara em colocar em prática uma politica de educação específica para o índio que não fosse a voltada para a integração. Antropólogos e linguistas eram chamados para darem pareceres sobre os convênios estabelecidos com as instituições religiosas, mas não para idealizarem e realizarem uma proposta de Educação Escolar Indígena." (KAHN e FRANCHETTO, 1994, p. 6)

Este cenário, conforme mencionado anteriormente, muda positivamente em relação às populações indígenas brasileiras, incluída a EEI, a partir dos anos de 1980 quando "haverá uma mudança neste quadro" (cf. KAHN e FRANCHETTO, 1994, p. 6). Na verdade, de acordo com as autoras,

“Os anos 80 foram o marco na afirmação dos movimentos indígenas organizados no Brasil, motivados também pelo caminho construído pelas organizações civis de apoio ao índio para a conquista dos seus direitos formais, garantidos em lei, via Constituição. Foi, então, o início de uma mobilização dos próprios sujeitos índios para conquistas políticas que vinham sendo lançadas na arena de um país que sempre se orgulhou de sua democracia racial e uniformidade linguística".

Como resultado da mobilização dos sujeitos índios, conquista-se

“...a inédita aceitação do direito dos índios de serem diferentes, uma conquista que tentará romper com a tradição assimilacionista que prevalecia nas legislações anteriores... surgiram leis promissoras para um país onde as formas de intervenção definidas pelo Estado preocupavam-se primordialmente em evitar a destruição física dos povos indígenas, mas, em contrapartida, assumiam como inevitável o desaparecimento das culturas indígenas. A experiência histórica demonstrava, entretanto, que o processo de mudança desencadeado pela presença dos brancos majoritários ao redor das sociedades indígenas conduzia a reformulações socioculturais, mas não à transformação dos índios em não-índios; conseguiu-se que esta constatação fosse assimilada pela nova legislação através do reconhecimento da existência e manutenção das minorias étnicas no país." (KAHN e FRANCHETTO, 1994, p. 6-7) 
Ao longo das distintas fases pelas quais passou a EEl, os povos indígenas e suas línguas sofreram enormes danos. Ribeiro (1957, apud LEITE e FRANCHETTO, 2006) "estima em 1.000,000 a população indígena na época da chegada da frota de Cabral, que teria baixado para um máximo de 100.000 no século atual". No que confere à quantidade de línguas, Rodrigues (1993, apud LEITE e FRANCHETTO, 2006) "estima que, às vésperas da conquista, eram faladas 1273 línguas...São cerca de 180 línguas,... para uma população que se distribui em 41 famílias, dois troncos, uma dezena de línguas isoladas". A perda de aproximadamente 1.000 línguas indígenas atestada ao longo dos mais de 500 anos "pós-Cabral", segundo Seki (2000, p. 238), se deve:

“...ao desaparecimento físico dos falantes, em decorrência de epidemias, extermínio direto, escravização, redução de territórios, destruição das condições de sobrevivência e aculturação forçada, entre outros fatores que sempre acompanharam as frentes de expansão desde o período colonial até nossos dias."

As historias dos povos indígenas brasileiros e suas línguas quando contadas pela perspectiva não indígena parecem bastante pessimistas, sobretudo quando observadas pelo cenário aqui descrito para o período anterior aos anos de 1980. Ocorre que os anos posteriores à década de 1980 têm-nos mostrado uma perspectiva bastante otimista em relação aos mesmos povos e línguas. Eles têm crescido demograficamente, têm instaurado políticas e ações de salvaguarda de seus conhecimentos, ciências, culturas; têm promovido a língua no sentido de mantê-la como meio de comunicação cotidiana entre seus pares. É um momento em que vivenciamos décadas de protagonismo indígena. No caso da escola indígena, protagonismo através do qual buscam meios para entendê-la e promovê-la como instrumento a serviço de seu povo, de suas necessidades e de seus interesses.

Em meio a essa escola, note-se a presença do Português Brasileiro (PB), objeto deste artigo. Assim sendo, tratamos na seção seguinte das diretrizes gerais referentes ao PB nas escolas não indígenas e indígenas (2); de caminhos para a especificidade, pelo PB, na escola indígena (3); da instauração de atitudes de respeito recíproco, pelo PB em uso, entre as mesmas escolas (4). Após esse percurso, apresento as Considerações Finais do artigo (5).

\section{O PB na Educação Escolar não Indígena e na Educação Escolar Indígena: diretrizes ge- rais}

A inserção do ensino de língua portuguesa ${ }^{3}$ no currículo da escola não indígena brasileira ocorre somente nas últimas décadas do século XIX. Segundo Soares (2004, p. 157), essa língua até então “...estava ausente não só do currículo escolar, mas também, de certa

\footnotetext{
${ }^{3}$ Utilizo a nomenclatura língua portuguesa nesta seção do artigo em conformidade com a fonte citada (SOARES, 2004; BRASIL, 1997, 1998). Para além destas fontes, ao longo do texto, o leitor notará uso padronizado da nomenclatura Português Brasileiro (PB).
} 
forma, do próprio intercurso social...". Como disciplina escolar, a língua portuguesa manteve de seu início "até os anos 40 do século XX a tradição da gramática, da retórica e da poética." (cf. SOARES, 2004, p. 164). Em virtude do acesso à escola de públicos oriundos das camadas populares da sociedade, segundo Soares, op. cit., começa a ocorrer a partir dos anos de 1950 "uma real modificação no conteúdo da disciplina português", de modo que hoje se pense em uma disciplina que considere como objeto de ensino o uso, as variações linguísticas, as particularidades regionais, o texto e o contexto, a língua viva.

As mudanças de paradigmas relacionadas ao papel / lugar da língua portuguesa na escola ocorridas nas últimas décadas podem ser observadas nas diretrizes nacionais para a Educação Básica brasileira expressas nos Parâmetros Curriculares Nacionais (PCNs, BRASIL, 1997). Numa perspectiva ampla, segundo tais diretrizes, as aulas de língua portuguesa devem favorecer ações cujo efeito permita aos alunos ser capazes, dentre vários outros aspectos, de ler de maneira competente textos de diferentes gêneros e utilizando-se de estratégias diversas; utilizar a linguagem oral com eficácia, sabendo adequá-la a intenções e situações comunicativas que requeiram conversar num grupo, etc; produzir textos escritos coesos e coerentes; reconhecer a intencionalidade implícita e conteúdos discriminatórios ou persuasivos. Em síntese, o aluno deve usar de maneira competente a língua oral e a língua escrita, conforme suas necessidades comunicativas e contextuais.

Ao pensarmos em contextos relacionados aos usos da(s) língua(s), concluímos que as diretrizes dos PCNs para o ensino de língua portuguesa na Educação Básica não devem ser tomadas como eficientes para o contexto das escolas indígenas. Isto porque, como sabemos, há uma variação enorme em solo brasileiro relacionada ao uso, ao domínio, aos objetivos da língua portuguesa entre as diferentes populações indígenas. Da mesma forma, não dá, do ponto de vista psicolinguístico, para pensarmos proficiências semelhantes entre tais povos dadas as suas características de contato e "domínio" do PB; distintos em diferentes graus. Como consequência, a importância e o papel dados à língua portuguesa não são homogêneos entre as mesmas populações indígenas. Nesse sentido, na intenção de refletir as especificidades das populações indígenas brasileiras quanto ao ensino de português, surge o Referencial Curricular Nacional para as Escolas Indígenas (RCNEI, BRASIL, 1998), onde constata-se ênfase dada a esta língua como meio através do qual as sociedades indígenas acessarão (interpretarão e compreenderão) as diversas leis, documentos, contratos, títulos, registros e estatutos que norteiam nosso país. Ademais, segundo o RC$\mathrm{NEI}$, é pelo português que as mesmas sociedades interagirão com os aspectos econômicos do país; terão acesso às tecnologias disponíveis; num sentido inverso, também pelo uso do português, será possível se revelarem junto à sociedade não indígena. A este respeito, o RCNEl afirma que:

"Os textos produzidos em língua portuguesa, ou para ela traduzidos, nas escolas e comunidades indígenas, têm sido uma forma privilegiada de divulgação dos conhecimentos tradicionais e de afirmação étnica. Esses materiais fornecem dados importantes sobre as diferentes culturas indígenas e suas tradições, permitindo que, através deles, a diversidade cultural no 
país torne-se mais evidente e possa ser mais respeitada." (RCNEI, BRASIL, 1998, p. 121).

Considerando-se os aspectos mencionados acima, dentre outros referentes às sociedades indígenas brasileiras, o RCNEI indica como diretrizes para a Educação Básica da escola indígena ações cujo efeito permita aos alunos ser capazes, por exemplo, de lidar com formulários e questionários; de identificar a interação entre aspectos verbais e não verbais de textos como anúncios, folhetos e cartazes; de identificar diferentes aspectos de textos do dia a dia e de textos formais, incluídos atas, ofícios, jornais e revistas. Como podemos observar, trata-se de uma perspectiva funcional de ensino / uso do português.

Esta perspectiva ampla para o ensino de PB na escola indígena contrasta com a perspectiva delineada para a escola não indígena, ao mesmo tempo em que evidencia o lugar desta língua em ambas as escolas. Como vimos, entretanto, trata-se de lugares e funções distintas para esses dois modelos de escola nacional. O quadro a seguir sintetiza sem a intenção de ser exaustivo - algumas características desta língua para os dois modelos:

Quadro: O PB não indígena e o PB indígena.

\begin{tabular}{ll}
\hline O PB NA EDUCAÇÃO ESCOLAR NÃO INDÍGENA & O PB NA EDUCAÇÃO ESCOLAR INDÍGENA \\
\hline Língua oficial & Língua não oficial \\
\hline Língua materna & Língua não materna \\
\hline Professor falante nativo de PB & Professor (quase sempre) falante nativo de PB \\
\hline Obrigatória presença na sala de aula & Presença opcional na sala de aula \\
Baseado na norma & Baseado no uso \\
\hline "Português Padrão" & "Português Indígena" \\
\hline
\end{tabular}

Este quadro nos mostra sobretudo a existência de "dois PBs", o PB não indígena, assentado na norma, e o PB indígena, assentado no uso, na funcionalidade. Interessa-nos na sequência desse artigo apontar para algumas características que têm sido apontadas como inerentes ao português usado por populações indígenas. Ao assim fazê-lo, como veremos na seção seguinte, apontamos para o fato de que este português não apresenta nada extraordinariamente distinto daquilo que falantes de PB não indígena produzem. Essa compreensao terá impacto seja na escola indígena, que deve perguntar-se sobre o papel e a função do português em seu interior, seja na escola não indígena, que deve formar seu cidadão com a capacidade de respeitar a diversidade linguística brasileira.

\section{O PB na Educação Escolar Indígena: caminhando para a especificidade}

A sociedade brasileira, como inúmeras outras, alimenta a tradição de classificar tudo. Somos uma sociedade de rótulos. Como usuários do PB, transpomos essa tradição para o domínio da língua, motivo pelo qual ouvimos rótulos do tipo "português caipira", "português nortista", "português sulista", "português padrão / culto", "português indígena", den- 
tre outros. É necessário lembrar, contudo, que tais rotulações não são ingênuas ou neutras; há uma série de questões ideológicas e de poder envolvidas. A escola seguramente insere-se nesse contexto. Ela tem se constituído ao longo da história um meio através do qual tais questões tentam se perpetuar. Deste modo, sobretudo os dois últimos rótulos mencionados - "português padrão / culto" e "português indígena" - ganham relevância no sentido de que carregam em si valores potencialmente positivos e valores potencialmente negativos. Em termos estruturais, todavia, o que é o português padrão / culto? $O$ que é o português indígena?

A primeira pergunta acima nos faz lembrar exatamente que vivemos sob a pretensa ideia de um Português padrão / culto. Mas o que é isso? É um português sem problemas de concordância? É uma forma rebuscada de falar? Estruturas com léxico arcaico? Conceitos tais como coesão, coerência, clareza não podem servir de argumento para esta modalidade da língua, já que os utilizamos cotidianamente, mesmo como falantes de português ribeirinho ou quilombola das mais distintas regiões do país. A prova de seus usos é o fato de que conseguimos nos comunicar em diversas modalidades / registros deste português. Mas este português padrão / culto só existe / se sustenta na modalidade escrita da língua, então? Estaríamos diante de uma dicotomia em que de um lado (na escrita) estaria o português padrão / culto e, por outro lado, (na oralidade) estaria o português "errado", "vulgar"? Mas o português com problemas de concordância, sem rebuscamento, com sentenças simples é identificado no texto escrito também. Esse conjunto de perguntas nos mostra, portanto, quão complexa é a tentativa de definir esse "tal português padrão / culto".

O português indígena, por seu turno, é um rótulo que refere uma diversidade de usos desta língua; usos por populações indígenas com histórico de contato já bastante antigo, outros, nem tanto. Assim como mencionado para o caso do PB padrão / culto, não sabemos exatamente o que é essa modalidade da língua em termos estruturais. $O$ que temos de concreto acerca disto são análises pontuais para algumas formas de usos do PB. Nesse sentido, vemos o caso Tapirapé apresentado por Gorete Neto $(2012$, p. 5), onde se constata "mobilidade sintática flexível com alternâncias na ordem sujeito, verbo, objeto, sem comprometimento da compreensão textual; circularidade... o que poderia erroneamente dar ideia de repetição ou redundância". Para o caso do Português Indígena Kaingang, por exemplo, Silva (2011, p. 31) afirma que "é comum a ausência de concordância, na maioria das vezes, entre o verbo e seu sujeito e também entre um nome e seus complementos dentro de um sintagma". Gomes (2012) - a partir de textos produzidos por professores indígenas entre os anos de 2010 e 2011 no âmbito da Licenciatura Intercultural Indígena da Universidade Federal do Amapá, Campus Binacional, município de Oiapoque, estado do Amapá - mostra a ocorrência no português escrito usado por esses professores de apagamento de fricativas em final de palavra, de ausência de determinantes e de concordância entre sintagmas nominais, de não apagamento de cópia (argumento), de não preenchimento de núcleo, de uso irregular de sinais de pontuação e de elementos coesivos.

As características apresentadas acima para distintas formas de uso do PB não são 
extravagantes ou mesmo surpreendentes do ponto de vista linguístico no sentido de que muitas delas também são identificadas por falantes que têm o PB como língua materna. Para visualizarmos tais semelhanças, basta imaginarmos quantos de nós, falantes "nativos de PB", ainda produzimos (ou não) segmentos fricativos em final de palavra; quantos de nós produzimos textos ricamente redundantes em termos de informações; quantos de nós temos dificuldades em utilizar adequadamente os sinais de pontuação no texto escrito, etc. Ao pensarmos em concordância, por exemplo, quantos de nós a temos utilizado de maneira adequada seja no texto oral, seja no texto escrito? Aliás, atualmente, nos têm parecido bastante ameaçados os mecanismos de concordância do PB. Em seu lugar, o uso de nome nu está cada vez mais frequente, a marcação de número no sintagma está cada vez mais restrita ao determinante; no caso de sintagmas nominais e de sintagmas verbais que marcam relação de sujeito e de predicado, tem-se no SN o único lugar de uso das categorias gramaticais, etc. Esta(ría)mos diante de usos guiados para o léxico e não para a gramática. Tal característica reflete o usuário em seu vigor linguístico - independentemente se indígena ou não indígena - com suas sinapses, analogias, tentativas, (re)construções da língua. Isto se vê claramente quando observamos este ou aquele grupo utilizando o PB com marcas próprias de sua língua materna. Entre os Kaingang já mencionados, por exemplo, a ausência de concordância no uso do PB é atribuída a analogias feitas por este grupo à sua própria língua ${ }^{4}$. Sincronicamente, presenciamos no PB um momento de efervescência linguística com efeito direto sobre a morfologia; num estágio natural de mudança linguística operado por princípios de economia.

Diante desse cenário em que não se distingue claramente do ponto de vista estrutural / gramatical o usuário que tem o PB como língua materna e o usuário que o tem como língua adicional, somos levados a considerar legítimo o fato de que tais usuários apresentam as mesmas características: a de um PB capaz de satisfazer suas necessidades comunicativas. Esse é o usuário real, que se opõe à ideia de um usuário / falante perfeito, que use a língua de maneira irretocável. Convergimos, desta maneira, para um usuário indiscriminado da língua, que se apoia no estágio sincrônico da língua e seus mecanismos. O rótulo português indígena, assim, parece não fazer muito sentido. Para justificá-lo, precisaríamos pensar rótulos que dessem conta do PB usado por ribeirinhos, por quilombolas, por adolescentes da Geração Y; uma lista infindável de rótulos capazes de exprimir usos com características particulares. Desta forma, negamos neste artigo o rótulo Português Indígena em favor da expressão português brasileiro em uso por populações indígenas; assim mesmo, sem siglas. Consideramos, sobretudo, a generalidade do rótulo em questão e sua consequente "incapacidade" de exprimir a diversidade de usos do PB por distintas populações

\footnotetext{
${ }^{4}$ A este respeito, Silva (2011, p. 37) afirma que "No Kaingang, a função do sintagma nominal / sujeito é dada pela presença de um marcador morfológico posposto. Essa marcação é independente do verbo. Assim, o verbo pode estar em uma ação plural e os seus argumentos permanecem no singular ou vice- versa, o marcador de mudança de número do nome restringe somente o sintagma nominal, não gera uma relação obrigatória com o núcleo do sintagma verbal. Já no Português padrão, a relação entre o sintagma nominal e o núcleo do sintagma verbal é obrigatória, expressa morfologicamente pela flexão verbal".
} 
indígenas em solo brasileiro.

Na perspectiva aqui assumida e considerando que sequer sabemos o que é o PB padrão / culto, argumentamos em favor de que a escola indígena não seja atrelada unicamente à discussão relacionada ao PB "certo" ou "errado"; de que a aula de PB na escola indígena não seja atrelada a rótulos metalinguísticos. Ao contrário, a escola indígena deve estabelecer estratégias que potencializem o uso e o aprendizado do PB para fins de comunicação. Esta deve ser-Ihe uma concepção primária; gramática, norma, categorias funcionais tornam-se-lhe secundárias, não o meio que justifique sua existência.

Agir na sala de aula de língua portuguesa da escola indígena levando-se em consideração outra perspectiva que não voltada à comunicação, a um usuário pleno da língua, terá impacto não apenas no aluno aprendiz e sua relação com a língua e consigo mesmo mas, sobretudo, sobre sua a identidade (de usuário desta língua) e a identidade de seu povo. Na verdade, a escola indígena precisa entender que pensar o PB usado por sua população, em suas especificidades, como problema nos leva a questões de violências simbólicas. É violento rotular como usuário "incorreto" do PB um aluno que não o utiliza no dia a dia, que o tem como língua adicional, que o aprendeu tardiamente e na escola; uma língua que, sequer, é próxima geneticamente de sua língua, que não é a língua mais importante de seu convívio com outros povos indígenas, que é conhecida apenas pelos homens mais jovens de sua comunidade, etc. A escola indígena, portanto, precisa definir claramente o papel e a função do PB em seu interior. Não pode aceitá-lo sem discussões suficientes para delinear seu lugar na escola e, consequentemente, na própria comunidade. Assim, contribuirá eficazmente para que as conquistas iniciadas nos anos de 1980 se solidifiquem e, ao mesmo tempo, se ampliem.

\section{O PB e a escola indígena e não indígena: caminhando para o respeito reciproco}

A escola indígena, ao entender que lida com usuários potenciais e competentes do $\mathrm{PB}$, e que tais usuários não se constituem por responder corretamente essa ou aquela questão de exercício proposto, mas por usar a língua conforme suas necessidades e estágios de proficiência, torna-se uma escola mais útil a seu aluno. Isto ocorre porque a dinâmica da aula de PB se volta para o que o aluno sabe / usa e para o que precisará aprender / usar para incrementar ainda mais suas habilidades comunicativas, interacionais, e não para colecionar listas e listas de conceitos da gramática do PB. A escola volta-se, nessa perspectiva, a um usuário funcional da língua, quer saber o que seu aluno precisa para se comunicar; consequentemente, oferecer-lhe as ferramentas para tal. A argumentação, seja no texto oral, seja no texto escrito, será o fio condutor. Assim sendo, a escola indígena respeita seu aluno, ao mesmo tempo em que valoriza suas potencialidades e interesses.

À esta escola indígena, fugir da dicotomia certo / errado, bem como das listas e listas de conceitos da gramática do PB, permite-Ihe assentar-se nos pressupostos da decolonialidade, entendidos aqui - sem a pretensão de discussões teóricas - como um conjunto de práticas escolares capazes de valorizar a própria ciência do povo em que a referida es- 
cola se insere. As ciências desta escola não são apenas a que lhe chega via programas oficiais de ensino "sugeridos" pelas secretarias executivas de educação, mas aquelas do povo, construídas ao longo de milênios de sabedoria transmitida pela oralidade de geração em geração. Ao assumir para si práticas decoloniais em favor de suas ciências, a escola indígena deve questionar o valor e a função do PB que lhe chega. Nesse sentido, o modelo de escola em questão deve favorecer a busca de respostas para perguntas tais como: (i) "O que / como fazer na escola indígena com o PB?; (ii) É realmente necessário / possível pensar uma modalidade padrão / culto de uso do PB entre as populações indígenas brasileiras?; (iii) Qual o impacto de tudo isso sobre concepções de diferenças e de identidades linguísticas, tão discutidas no âmbito do pós-colonialismo?

Dado que a escola indígena não está alheia à realidade nacional e que, de certa forma, ainda busca, por diversos motivos, inspiração na escola não indígena, interessa-nos pensar aqui também um conjunto de perguntas para esta escola, a não indígena, qual seja: "O que esta tem feito em relação ao PB não padrão / culto? Esta escola tem obtido êxito na direção do uso da modalidade padrão / culto da língua? Ela pode ajudar a pensar o ensino de PB na escola indígena? Quando a escola não indígena sabe que seu aluno verdadeiramente compreendeu suas aulas para além de metalinguagem, tornando-se um usuário competente da língua?

Ao elencarmos as perguntas em questão e buscarmos respostas a elas conseguimos ver que a escola não indígena pode nos dizer coisas sobre o PB em seu interior, portanto. Outrossim, é bastante provável que as respostas às perguntas feitas para a escola não indígena ainda não sejam completamente convincentes, ou mesmo, estejam delineadas. Sobretudo quando pensamos a questão referente ao êxito no ensino da modalidade padrão / culto da língua, parece-nos haver, dentre sucessos, algum insucesso. 0 mesmo vale para respostas referentes à habilidade de uso competente. Assim, sem ignorar os resultados positivos da escola não indígena, nos parece bastante razoável pensar perspectivas para a escola indígena que não tenham como modelo unicamente a escola não indígena. Mais uma vez, a população, o usuário, as ciências indígenas tornam-se o ponto de partida e de chegada. Por outro lado, a escola não indígena não está isenta da questão do PB em uso por populações indígenas. Ao contrário, esta escola é responsável por formar as futuras gerações, capazes de respeitar as mais diversas formas de uso do PB, quer seja por falantes nativos, quer seja por falantes não nativos, como os aproximadamente 150 povos indígenas que ainda têm como língua materna outras que não o PB.

No caso das gerações atuais, a escola não indígena deve mostrar-Ihes a brutalidade presente em cada ato discriminatório desferido às populações indígenas pela língua. Utilizar os diferentes usos linguísticos destas populações como argumento para alimentar imagens negativas das populações indígenas brasileiras só nos mostra que ainda vivemos em uma sociedade que desvaloriza sua historia interna, a das inúmeras nações indígenas que verdadeiramente colonizaram essas terras, em virtude de uma historia externa, a dos colonizadores. Para opor-se a esse cenário de maneira responsável, a escola não indígena precisa apropriar-se do conceito de interculturalidade, tão discutido e pensado para a es- 
cola indígena. Aliás, a esse respeito, à guisa de finalização deste artigo, cumpre-nos perguntar se têm chegado ao ambiente da escola não indígena discussões relacionadas à interculturalidade!? Para o caso de respostas ainda pouco definidas, cabe-nos ainda perguntar: porque pensar interculturalidade apenas para dentro da escola indígena? A título de exemplo ilustrativo da aparente ausência desta discussão na escola não indígena, perguntamos quantos alunos do sistema educacional brasileiro da Educação Básica sabem a quantidade de línguas indígenas faladas em território nacional? Quantos sabem da historia de contato destas populações para além do estereotipo criado em torno do ano 1500? Finalmente, consideramos que enquanto a escola não indígena não assumir seu papel intercultural, seremos levados a pensar que apenas a escola indígena deve ser. Mas o que isso significa? Que esta escola deve falar de culturas que não a sua? A escola não indígena não deve, ou apenas deve falar da cultura de povos europeus, como ainda tem feito? Isso não seria uma espécie de resquício do modelo assimilacionista vivenciado recentemente no Brasil?

O conjunto de perguntas acima referentes à escola não indígena, deve-nos fazer pensar que a Lei 11.645/08 - que torna obrigatório nos estabelecimentos de ensino fundamental e de ensino médio, públicos e privados, o estudo da história e cultura afrobrasileira e indígena - não pode ser jogada ao esquecimento, não pode contar com nossa indiferença mas, ao contrário, nos deve servir de incentivo para a construção de respostas otimistas e positivas. Ao não esquecê-la e, consequentemente, favorecer em seu interior ações que culminem no conhecimento, pelas populações não indígenas, das populações indígenas brasileiras em suas especificidades, a escola não indígena contribuirá para a formação de uma sociedade mais justa em que o escopo seja a formação de cidadãos que respeitem, pela lingua, o outro, não de pessoas insensíveis à diversidade de povos, culturas, línguas, cosmologias, cosmovisões, etc. inerentes àquilo que denominamos Brasil.

\section{Considerações Finais}

Como vimos, pensar o lugar / ensino de PB nas escolas indígena e não indígena nos põe diante de alguns dilemas, dentre os quais reiteramos a necessidade de pensar o valor, o propósito, a natureza do PB usado por populações indígenas; os modelos possíveis de ensino que considerem / partam da própria população atendida pela escola, utilizando-se de práticas verdadeiramente decoloniais; a interculturalidade como processo inerente ao sistema educacional e não como conceito particular / aplicável apenas à escola indígena; a importância de discutir, na escola não indígena, pela língua, a relevância das populações indígenas para o Brasil em diferentes aspectos históricos e contemporâneos.

Discussões nesse sentido envolvem um conjunto amplo de pessoas que inclui representantes de secretarias executivas de educação, professores indígenas e não indígenas de todos os níveis da Educação Básica, linguistas (aplicados ou não), pedagogos e, claro, principalmente, a comunidade indígena em que está inserida a escola. O ponto de partida comum a todos, vale lembrar, não será a prescrição, a concepção de um uso inadequado do 
PB, mas a concepção de que a língua é viva, de que seu aprendizado é dinâmico e pautase, sobretudo, na convivência, no contato; a concepção de que os fins e os usos são distintos para / na escola indígena e não indígena. Escola não indígena, repense a forma como tem instruído seus alunos para a diversidade linguística. Escola indígena, não aceite fórmulas prontas de ensino de PB em seu interior, principalmente aquelas involucradas no rótulo Programa de Língua Portuguesa da série $X$ ou Y. Antes, pense, descubra qual sua real intenção no ensino e na aprendizagem desta língua. Experimente fazer essa pergunta à comunidade que você atende. A partir da resposta, construa e trilhe seus próprios caminhos. Autonomia e clareza de objetivos lhes servirão de suporte para uma caminhada exitosa. Usem o poder por vocês construído ao longo de milênios de sabedorias!

\section{Referências}

BRASIL. Lei N. 11.645/08, de 10 de março de 2008.

BRASIL. Lei N. 10.172, de 9 de janeiro de 2001.

BRASIL. Referencial Curricular Nacional para as Escolas Indígenas (RCNEI). Brasília: MEC/SEF, 1998.

BRASIL. Parâmetros Curriculares Nacionais (PCNs). Língua Portuguesa. Ensino Fundamental, $3^{\circ}$ e $4^{\circ}$ Ciclos. Brasília: MEC/SEF, 1997.

BRASIL. Constituição da República Federativa do Brasil. Brasília, DF, Senado, 1988.

FERREIRA, M. K. L. Da origem dos homens à conquista da escrita: um estudo sobre povos indígenas e educação escolar no Brasil. Dissertação de Mestrado. Universidade de São Paulo, 1992.

GOMES, A. A. S. Estágio Curricular na área de Linguagens e Códigos: um estudo de caso na Licenciatura Intercultural Indígena. Olhares, v. 1, 2013, p. 269-296.

GOMES, A. A. S. Português brasileiro em uso por professores indígenas do estado do Amapá. Anais do SIELP. volume 2, Numero 1. Uberlândia: EDUFU, 2012. Disponível em: http://www.ileel.ufu.br/anaisdosielp/wpcontent/uploads/2014/06/volume_2_artigo_037.pdf. Acesso em 10 de setembro de 2017. GORETE NETO, M. Português-indígena versus português-acadêmico: tensões, desafios e possibilidades para as licenciaturas indígenas. Anais do SIELP. volume 2, Numero 1. Uberlândia: EDUFU, 2012. Disponível em: http://www.ileel.ufu.br/anaisdosielp/wpcontent/uploads/2014/07/volume_2_artigo_213.pdf. Acessado em 12 de março de 2017. IBGE. Censo Demográfico 2010. Disponível em: <http://www. censo2010.ibge.gov.br> LEITE, Y.; FRANCHETTO, B. "500 anos de línguas indígenas no Brasil”. In: Suzana A. M. C.; MOTA, J. A; MATTOS E SILVA, R. V. (Orgs). Quinhentos anos de História Linguística do Brasil. Salvador: Secretaria da Cultura e Turismo do Estado da Bahia, 2006, p. 15-62.

KAHN, M.; FRANCHETTO, B. Educação indígena no Brasil: conquistas e desafios. Em Aberto, Brasília, ano 14, n.63, jul./set. 1994, p. 4-9.

LEITE, Y. F.; FRNCHETTO, B. 500 anos de Línguas Indígenas no Brasil. In: Suzana Alice Marcelino Cardoso, Jacyra Andrade Mota e Rosa Virgínia Mattos e Silva. (Orgs). 500 anos de 
História da Linguística no Brasil. 1ed.Salvador: Funcultura, 2006, p. 15-61.

MOORE, D; GALUCIO, A. V; GABAS JÚNIOR, N. O Desafio de Documentar e Preservar as Línguas Amazônicas. Revista Scienfic American Brasil (Edição Especial), v.3, 2008, p. 36-43.

SEKI, L. Línguas indígenas do Brasil no limiar do século XXI. Revista Impulso, n. 27, 2000, p. 233-256.

SILVA, M. L. Português indígena Kaingang: uma questão de concordância. Dissertação de Mestrado. Universidade Estadual de Campinas, 2011. Disponível em http://repositorio.unicamp.br/handle/REPOSIP/269215. Acessado em 12 de março de 2017.

SOARES, M. Português na escola: historia de uma disciplina curricular. In. BAGNO, M. Linguística da Norma. Edições Loyola, $2^{\mathrm{a}}$ Ed. 2004, p. 155-178. 